Research Article

\title{
Climate Change Impacts on Winter Wheat Yield in Northern China
}

\author{
Xiu Geng, ${ }^{1,2}$ Fang Wang $\mathbb{D}^{1,2}$ Wei Ren, ${ }^{3}$ and Zhixin Hao $\mathbb{I}^{1,2}$ \\ ${ }^{1}$ Key Laboratory of Land Surface Pattern and Simulation, Institute of Geographic Sciences and Natural Resources Research, \\ Chinese Academy of Sciences, Beijing 100101, China \\ ${ }^{2}$ College of Resources and Environment, University of Chinese Academy of Sciences, Beijing 101408, China \\ ${ }^{3}$ College of Agriculture, Food and Environment, University of Kentucky, Lexington 40506, USA \\ Correspondence should be addressed to Zhixin Hao; haozx@igsnrr.ac.cn
}

Received 22 February 2019; Revised 6 May 2019; Accepted 19 May 2019; Published 19 June 2019

Guest Editor: Sushil K. Dash

Copyright (C) 2019 Xiu Geng et al. This is an open access article distributed under the Creative Commons Attribution License, which permits unrestricted use, distribution, and reproduction in any medium, provided the original work is properly cited.

\begin{abstract}
Exploring the impacts of climate change on agriculture is one of important topics with respect to climate change. We quantitatively examined the impacts of climate change on winter wheat yield in Northern China using the Cobb-Douglas production function. Utilizing time-series data of agricultural production and meteorological observations from 1981 to 2016, the impacts of climatic factors on wheat production were assessed. It was found that the contribution of climatic factors to winter wheat yield per unit area (WYPA) was $0.762-1.921 \%$ in absolute terms. Growing season average temperature (GSAT) had a negative impact on WYPA for the period of 1981-2016. A 1\% increase in GSAT could lead to a loss of $0.109 \%$ of WYPA when the other factors were constant. While growing season precipitation (GSP) had a positive impact on WYPA, as a $1 \%$ increase in GSP could result in $0.186 \%$ increase in WYPA, other factors kept constant. Then, the impacts on WYPA for the period 2021-2050 under two different emissions scenarios RCP4.5 and RCP8.5 were forecasted. For the whole study area, GSAT is projected to increase $1.37^{\circ} \mathrm{C}$ under RCP4.5 and $1.54^{\circ} \mathrm{C}$ under RCP8.5 for the period 2021-2050, which will lower the average WYPA by $1.75 \%$ and $1.97 \%$, respectively. GSP is tended to increase by $17.31 \%$ under RCP4.5 and $22.22 \%$ under RCP8.5 and will give a rise of 3.22\% and $4.13 \%$ in WYPA. The comprehensive effect of GSAT and GSP will increase WYPA by 1.47\% under RCP4.5 and 2.16\% under RCP8.5.
\end{abstract}

\section{Introduction}

In recent years, the frequency of various meteorological disasters such as drought, flood, and frost has increased due to climate change, which seriously impaired many climatesensitive sectors [1]. It is understood that agriculture is likely to be affected most by climate change and variability because of its high dependence and sensitivity to climatic conditions [2-5]. Nevertheless, the impacts of climate change on crops in different regions are not the same [6]. Previous studies have shown that the warming caused by greenhouse gases is more pronounced at higher latitudes [7], which could lengthen growing seasons and reduce the risk of freezing injury due to low temperature and have positive effects on crops here $[8,9]$. In contrast, higher temperature will adversely affect growing conditions in lower latitudes, especially in areas where temperatures are close to or at the optimal level for crop growth to begin with $[10,11]$. Impacts on agriculture are likely to be especially severe in developing countries because of their low agricultural investment, technological levels, and capability to cope with climate change $[12,13]$. China is the most populous developing country as well as one of the largest agricultural production countries. Agriculture in China feeds $22 \%$ of the global population with only $7 \%$ of the world's arable lands [14]. However, some studies have shown that China's agriculture might suffer from climate change. The loss in yield for each degree Celsius increase in global mean temperature is about $8.0 \%$ for maize and $2.6 \%$ for wheat [15]. It is urgent for us to understand the possible impacts of climate change on China's agriculture production, so that the planting strategies can be provided timely to avoid or mitigate the negative impacts from climate change. 
There is now a substantial number of assessment studies demonstrating the link between climate change and agriculture, with the study methods ranging from simple equations to complex models, the study scope ranging from single sector to multiple sectors, and the study core ranging from intuitive phenomenon to mechanism analysis [16]. Crop models and statistical models are two main tools for quantitatively assessing the effects of climate change on crop yields [17]. Crop models such as DSSAT (America), APSIM (Australia), and CCSODS (China) can integrate knowledge on physiology, agronomy, soil science, and agrometeorology to the models using mathematical equations to quantitatively and dynamically describe the process of crop growth, development, and yield formation. Crop models are dominant tools for the Third and Fourth Assessment Reports of the IPCC to assess the impacts of climate change on agricultural sector because of their relatively clear ecological mechanism [18]. However, the results of crop models are highly sensitive to soil, meteorology, and field management and require extensive input data. These models also can be very difficult to calibrate because of complex model structures and a large number of uncertain parameters [19-22]. Statistical models such as time-series models, panel data models, and cross section models can predict crop indicators by using historical data on crop indicators and weather data to develop a regression equation [23]. However, the statistical data of Food and Agriculture Organization of the United Nation (FAO) showed that global wheat yield did not reduce with climate warming in the premise of stable planting areas (http:// www.fao.org/faostat/zh/\#data/QC/visualize), which indicated that with the development of agricultural technology, agricultural production is not only related to meteorological factors such as temperature and precipitation but also to economic factors such as labor and fertilizer. Therefore, researchers combined meteorological factors and economic factors as independent variables to establish regression models so as to explore the impacts of climate change on agricultural production [24-27]. Chou et al. $[28,29]$ developed a new model (C-D-C) for assessing and predicting the effect of climate change on grain yield by introducing climatic factors into the C-D (Cobb-Dauglas) production function, and the preliminary simulation and verification of the model were performed.

In terms of planting area and yield, wheat is the third most important crop in China, only behind rice and maize, and winter wheat accounts for approximately 95\% of the total (winter and spring) wheat yields. The northern winter wheat production areas (NWPA) are the main areas that produce winter wheat and make up approximately $80.1 \%$ of the wheat production (National Bureau of Statistics of China, http://data.stats.gov.cn/easyquery.htm?cn=E0103). Winter wheat is mainly used for food in this region because of its high quality and flour yield. The goal of this paper was to quantitatively study the impacts of climate change on the winter wheat yield per unit area (WYPA) in NWPA by introducing growing season average temperature (GSAT) and precipitation (GSP) for winter wheat into the C-D production function, so as to provide reference for planting strategies and wheat import and export trade strategies in the future.

\section{Materials and Methods}

2.1. Study Area and Data. Our study area covers Jing-Jin-Ji region (including Beijing, Tianjin, and Hebei provinces), Shanxi, Shaanxi, Shandong, and Henan provinces (Figure 1), located in the midlatitude temperate zones of northern hemisphere $\left(32-42^{\circ} \mathrm{N}\right)$ and influenced by East Asian monsoon climate. Crops are harvested twice a year or three times every two years. The climatic conditions in the region are suitable for planting winterness or strong-winterness wheat varieties with an annual precipitation of $440-980 \mathrm{~mm}$, annual average temperature of $9-15^{\circ} \mathrm{C}$, and active accumulated temperature ranges from 2750 to $4900^{\circ} \mathrm{C}$. The growing season of winter wheat in this area is from this September to next June [30, 31].

The data used in this study included meteorological data and agricultural data. The meteorological data consisted of observations data for estimating the parameters of models and scenario data for forecasting future climate change. Observations data were available from China Meteorological Administration (CMA), which provided time series on the daily temperature and precipitation of meteorological stations (black dots in Figure 1) across the study area from 1981 to 2016, so as to calculate the GSAT and GSP for winter wheat. Greenhouse gas emission scenarios are the basis for future climate change projections, and one of the most important scenarios is RCPs (representative concentration pathways). RCPs include four greenhouse gases concentration trajectories adopted by the IPCC AR5, which represent integrated socioeconomic standards, emissions, and climate scenarios to construct the definite mitigation scenario. The four RCPs including RCP2.6, RCP4.5, RCP6.0, and RCP8.0 stabilized the radiative forcing at approximately $490,650,850$, and $1370 \mathrm{ppm} \mathrm{CO}_{2}$-equivalent in 2100 , respectively [32]. RCP4.5, a medium emissions scenario, is possibly consistent with the future economic development of China and meets the mitigation plan for responding to climate change [33]. RCP8.5 corresponds to a high greenhouse gas emissions pathway and also to the upper bound of the four RCPs. The greenhouse gases emissions and concentrations in this scenario increase considerably over time, and there is not any specific climate mitigation target [34]. Therefore, the RCP4.5 and RCP8.5 were used in this study. Climate scenario data from the RCP4.5 and RCP8.5 for 2021-2050 were downloaded from the Inter-Sectoral Impact Model Intercomparison Project (ISI-MIP). The data include 5 climate models simulation outputs: HadGEM2-ES (MOHC, England), IPSL-CM5A-LR (IPSL, France), MIROC-ESM-CHEM (MIROC, Japan), GFDL-ESM2M (GFDL, America), and NorESM1-M (NCC, Norway), which have been bias-corrected based on the raw data from the 5 CMIP5 models listed above. The variability of the simulated data about their monthly means is modified to match the observed data to preserve the long-term absolute or relative trend of the simulated data. Then, these data are bilinearly interpolated in space to $0.5^{\circ} \times 0.5^{\circ}$ grid [35]. The 


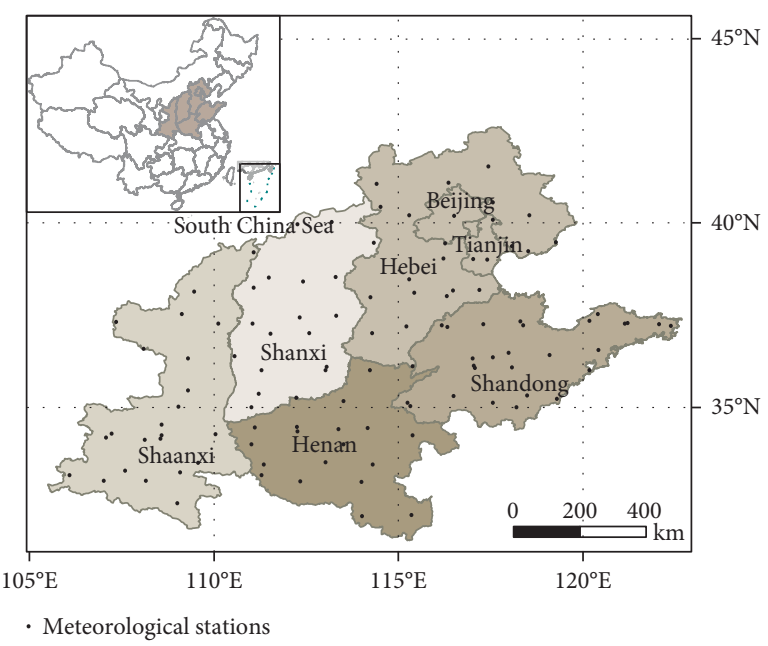

FIgURE 1: Location of study area and the distribution of meteorological stations.

multimodel ensemble (MME) of the climate variables was used in this paper, including daily mean temperature and precipitation.

Agricultural data were available from the National $\mathrm{Bu}-$ reau of Statistics of the People's Republic of China and an agricultural statistical datasets [36], which included provincial WYPA and related inputs from 1981 to 2016, that is, fertilizer use, machinery, labor, and irrigated area for winter wheat.

2.2. Model Specification and Evaluation. Cobb-Douglas production function is a multifactor analysis model, which can effectively describe the relationship between production factors and output. The production factors used in this study included both agricultural inputs and climatic factors, and we introduced climatic factors GSAT and GSP into the Cobb-Douglas production function to quantitatively investigate the impacts of climate change on wheat yield for the five provinces (region) in Northern China. We specified the empirical production function where the WYPA was a function of the meteorological variables and agricultural inputs for any province (region) $i$ at year $t$ :

$$
Y_{\mathrm{it}}=\alpha_{0} \times F_{\mathrm{it}}^{\alpha_{1}} \times M_{\mathrm{it}}^{\alpha_{2}} \times L_{\mathrm{it}}^{\alpha_{3}} \times I_{\mathrm{it}}^{\alpha_{4}} \times T_{\mathrm{it}}^{\beta_{1}} \times P_{\mathrm{it}}^{\beta_{2}} \times e^{\gamma \mathrm{T} \mathrm{e}_{\mathrm{it}}} \times e^{\varepsilon_{\mathrm{it}}} .
$$

We linearized the equation by taking the logarithm of both sides:

$$
\begin{aligned}
\ln \left(Y_{\mathrm{it}}\right)= & \alpha_{0}+\alpha_{1} \ln \left(F_{\mathrm{it}}\right)+\alpha_{2} \ln \left(M_{\mathrm{it}}\right)+\alpha_{3} \ln \left(L_{\mathrm{it}}\right) \\
& +\alpha_{4} \ln \left(I_{\mathrm{it}}\right)+\beta_{1} \ln \left(T_{\mathrm{it}}\right)+\beta_{2} \ln \left(P_{\mathrm{it}}\right)+\gamma \mathrm{Te}_{\mathrm{it}}+\varepsilon_{\mathrm{it}},
\end{aligned}
$$

where $Y$ was the WYPA $(\mathrm{kg} / \mathrm{ha})$ and the agricultural inputs $F, M, L$, and $I$ were fertilizers used (10,000 tons), machinery $(10,000 \mathrm{kw})$, labor $(10,000$ persons), and irrigated area (1000 ha) for winter wheat, respectively. More importantly, we introduced average temperature $\left(T,{ }^{\circ} \mathrm{C}\right)$ and precipitation $(P, 100 \mathrm{~mm})$ during winter wheat growing season (from this
September to next June) as climatic factors to the model. Additionally, we allowed for time varying effects on winter wheat production, represented by a time series, Te, and intended to capture the factor of technological progress influence. $\varepsilon$ was white noise. The $\alpha, \beta$, and $\gamma$ were the coefficients to be estimated.

One should note that the agricultural inputs for winter wheat were included in the total agricultural inputs and needed to be calculated by some formulas. They can take the following form:

$$
\begin{aligned}
F_{\mathrm{it}} & =\mathrm{TF}_{\mathrm{it}} \times \mathrm{RA}_{\mathrm{it}}, \\
M_{\mathrm{it}} & =\mathrm{TM}_{\mathrm{it}} \times \mathrm{RA}_{\mathrm{it}}, \\
L_{\mathrm{it}} & =\mathrm{TL}_{\mathrm{it}} \times \mathrm{RG}_{\mathrm{it}} \times \mathrm{RA}_{\mathrm{it}}, \\
I_{\mathrm{it}} & =\mathrm{TI}_{\mathrm{it}} \times \mathrm{RA}_{\mathrm{it}},
\end{aligned}
$$

where TF was total fertilizer use of farm crops; TM was total power of agricultural machinery; TL was total labor of agriculture, forestry, animal husbandry, and fishery; TI was total agricultural irrigated area; RA was sown area of winter wheat/total sown area of farm crops; RG was gross output of agriculture/gross output of agriculture, forestry, animal husbandry, and fishery.

Panel data involved two dimensions: a cross-sectional dimension and a time-series dimension [37], which required testing the temporal stability of variables before establishing a regression model to avoid spurious regressions. The approaches of LLC that assumes common unit root process [38] and ADF-Fisher that assumes individual unit root process [39] were used in this study to test for a unit root. The regression analysis can be carried out when all of the variables are stationary time series. However, as analyzed by Zhao [40], we can also establish a regression model if the variables pass the cointegration criterion in the premise that the integrated order of dependent variable is not more than that of independent variables and there are at least two independent variables having the integrated orders more than that of dependent variable, although some of the variables are nonstationary time series.

We adopted "leave-one-out cross validation" [41], the measures of "normalized root mean square error" (NRMSE), and "index of agreement" (IA) [42] to evaluate model performance. The two measures, NRMES and IA, summarize the average difference and agreement between observed and model-predicted values, respectively. They can take the following form:

$$
\begin{aligned}
\text { NRMSE } & =\sqrt{\frac{\sum_{1}^{n}\left(P_{i}-O_{i}\right)^{2}}{n}} \times \frac{100}{\bar{O}}, \\
\text { IA } & =1-\left[\frac{\sum_{1}^{n}\left(P_{i}-O_{i}\right)^{2}}{\sum_{1}^{n}\left(\left|P_{i}-\bar{O}\right|+\left|O_{i}-\bar{O}\right|\right)^{2}}\right],
\end{aligned}
$$

where $P_{i}$ is the model-predicted value, $O_{i}$ is observed value, $n$ is the number of cases, and $\bar{O}$ is the average of observed values. Following Yang et al. [43], we considered NRMSE $\leq 15 \%$ as "good" agreement; $15-30 \%$ as "moderate" 
agreement; and $\geq 30 \%$ as "poor" agreement. IA is intended to be a descriptive measurement, and it is both a relative and bounded measure [42], with IA $=0$ indicating no agreement and $\mathrm{IA}=1$ indicating perfect agreement or zero error. Also as recommended by Yang et al. [43], when IA $\geq 0.9$, it is considered as "excellent" agreement; $0.8 \leq$ IA $<0.9$ as "good" agreement; $0.7 \leq \mathrm{IA}<0.8$ as "moderate" agreement; and IA $<0.7$ as "poor" agreement.

The impacts of climate trends and agricultural inputs changes on the WYPA were calculated in the following processes. First, we set three scenarios: (i) actual climatic factors and actual agricultural inputs for each province (region) for the period 1981-2016; (ii) detrended climatic factors and actual agricultural inputs; (iii) actual climatic factors and fixed agricultural inputs. We obtained the detrended datasets of GSAT and GSP for winter wheat in the five provinces (region) by the method of "linear detrending" [44]. For the agricultural inputs, we fixed them at the values in 1980. They can take the following form:

$$
\begin{aligned}
& \mathrm{Cd}_{i, t}=\text { detrended climatic variable }=C_{i, t}-s_{i} * t, \\
& \mathrm{AF}_{i, t}=\text { fixed agricultural input }=A_{i, 1980},
\end{aligned}
$$

where $C_{i, t}$ is the climatic variable for province (region) $i$ at year $t$, including GSAT and GSP; $s_{i}$ is the slope of one climatic variable for province (region) $i$, based on linear fit for 1981-2016; and $A_{i, 1980}$ is the agricultural inputs for province (region) $i$ in 1980, including fertilizer use, machinery, labor, irrigated area, and technological progress. We then used the "Climate-Economy" model $F(C, A)$ to compute the following:

(i) $F(C, A)=$ predicted WYPA with observed climatic data and agricultural inputs

(ii) $F(\mathrm{Cd}, A)=$ predicted WYPA with detrended climatic data and observed agricultural inputs

(iii) $F(C, \mathrm{AF})=$ predicted WYPA with observed climatic data and fixed agricultural inputs

We computed the trends of (i)-(ii) and (i)-(iii) to quantify the yield effects of climate trends and agricultural inputs changes, respectively.

\section{Results}

3.1. Panel Regression and Model Evaluation. The results of unit root test suggested that a cointegration test should be carried out, and the variables passed the cointegration criterion (Table 1), which indicated that we can establish a regression model and the model will not be spurious. $F$ test suggested us to choose a fixed-effects model, and the estimation results are presented in Table 2 . We also reported the adjusted $R^{2}, F$ statistic, NRMSE, and IA used to evaluate the model performance in Table 2 . The value of adjusted $R^{2}$ was 0.91 , and $F$ statistic was significant at the $1 \%$ level, which indicated that the model had the feature of high fitting precision. NRMSE and IA were $8.14 \%$ and 0.98 , respectively, showing a high extrapolating performance of the model. The coefficients on all of the agricultural inputs were positive and significant as expected for WYPA, except the labor with a negative coefficient. This indicated that WYPA increased with more fertilizer use, machinery, and irrigation but decreased with more labor. The reason why labor had a negative impact on YWPA was explicable that, since 1980, the agricultural mechanization improved rapidly, which resulted in a large surplus of agricultural labor. For climatic factors, the sign was negative for GSAT and was positive for GSP. This suggested that WYPA increased with more precipitation and decreased with higher temperature during the growing season.

\subsection{Impacts of Climate Change on the Fluctuation of Winter} Wheat Yield. From Table 2, the elastic coefficient of temperature was -0.109 , which indicated that the WYPA will decrease $0.109 \%$ for each $1 \%$ increase in GSAT. Higher temperature negatively affect winter wheat yield, both directly and indirectly. With the increase of temperature, wheat tends to overgrow due to excessive accumulated temperatures before the winter, which makes wheat seedlings weak and lack resistance to the cold [45]. Higher temperature will also shorten winter wheat growing season, leading to the decrease of 1000-grain weight and damaging the quality of grain [46]. In addition, the occurrence probability of extreme high temperature events in the later stage of winter wheat growing season will increase, which is not conducive to the formation of wheat yield. However, due to the large demand of winter wheat for water and the low precipitation in study area, GSP had a positive and significant impact on WYPA, with the elastic coefficient of 0.186 , that is, each $1 \%$ increase in GSP will increase WYPA by $0.186 \%$. However, in the terms of the whole study area, GSAT for winter wheat experienced a significant increase by $0.49^{\circ} \mathrm{C}$ per decade since 1980 ; yet, the GSP had a slight but inconspicuous increasing trend with the slope of 1.138 (Figure 2).

Figure 3 showed the model-simulated results of $F(C, A)$, $F(\mathrm{Cd}, A)$, and $F(C, \mathrm{AF})$ for each province (region), so as to measure the impacts of climatic factors and agricultural inputs on WYPA. From Figure 3, agricultural inputs and technological progress played an important role in the formation of wheat yield. If these variables have remained at the values of the 1980s, the WYPA would be stagnant (green arrows). We computed the differences of $F(C, A)$ and $F(C$, $\mathrm{AF}$ ) for each province (region) to quantify the impacts of agricultural inputs on wheat yield variability and found that Shandong province was most influenced by agricultural inputs, followed by Jing-Jin-Ji region and Henan province, with the WYPA increase rate of $60.438 \%, 59.279 \%$, and $56.369 \%$, respectively. The effects of agricultural inputs on WYPA for Shanxi and Shaanxi provinces were less, and the WYPA only increased by $28.448 \%$ for Shanxi province and by $27.193 \%$ for Shaanxi province. However, the effects of climate trend on wheat yield were relatively low, and the degree of the effects was different within the five provinces (region). The actual climate change in Jing-Jin-Ji region and Shandong province, that is relatively weak rise in temperature (Jing-Jin- $\mathrm{Ji}_{\text {slope }}=0.032$; Shandong slope $=0.034$ ) and large increase in precipitation (Jing-Jin- $\mathrm{Ji}_{\text {slope }}=1.775$; 
TABLE 1: Unit root test and cointegration test.

\begin{tabular}{ccccccc}
\hline & $\ln Y$ & $\ln F$ & $\ln M$ & $1 \ln L$ & $\ln T$ & \multicolumn{1}{c}{$\ln P$} \\
\hline \multirow{2}{*}{ LLC } & $-5.73^{* * *}$ & $-8.08^{* * *}$ & $-4.21^{* * *}$ & $-1.63^{*}$ & -0.30 & $-6.48^{* * *}$ \\
& & & $-11.28^{* * *}$ & $-10.33^{* * *}$ & $-7.28^{* * *}$ \\
ADF & $48.25^{* * *}$ & $47.05^{* * *}$ & $18.24^{* *}$ & 12.22 & 7.23 & $77.30^{* * *}$ \\
& & & & $94.82^{* * *}$ & $86.39^{* * *}$ & $79.58^{* * *}$
\end{tabular}

Cointegration Test

ADF $-6.78^{\mathrm{a}}$

$*, * *$, and $* * *$ represent that the null hypothesis of nonstationary is rejected at $10 \%, 5 \%$, and $1 \%$ level, respectively. When there are two statistics in a cell, the top number is for the test on the original variable, and the bottom number is for the test on the variable after it has been differenced once. ${ }^{a}$ represents that the null hypothesis of no cointegration is rejected at $1 \%$ level.

TABle 2: Estimated parameters for fixed-effects model.

\begin{tabular}{lcc}
\hline Variables & Coefficient & Prob. \\
\hline$C$ & $6.192^{* * *}$ & $<0.001$ \\
$\ln F$ & $0.094^{* *}$ & 0.026 \\
$\ln M$ & $0.157^{* * *}$ & 0.004 \\
$\ln L$ & $-0.223^{* *}$ & 0.016 \\
$\ln G$ & $0.265^{* * *}$ & 0.008 \\
$\ln T$ & -0.109 & 0.327 \\
$\ln P$ & $0.186^{* * *}$ & $<0.001$ \\
Te & 0.003 & 0.361 \\
Fixed Effects (corss) & & \\
Jing-jin-ji_C & -0.088 & \\
Shanxi_C & 0.110 & \\
Shaanxi_C & 0.048 & \\
Shandong_C & -0.042 & \\
Henan_C & -0.028 & $<0.001$ \\
Model Performance Evaluation & & \\
Adj R & & \\
F-statistic & 0.91 & \\
NRMSE & $167.70^{* * *}$ & \\
IA & $8.14 \%$ & \\
\hline
\end{tabular}

$* *$ and $* * *$ represent the parameters are significant at the $5 \%$ and $1 \%$ levels, respectively.

Shandong slope $=1.116$ ), positively affected the wheat yield in the two regions during 1981-2016. The WYPA increased by $1.884 \%$ for Jing-Jin-Ji region and by $0.762 \%$ for Shandong province, relative to those without the climate trend. On the contrary, due to relatively rapid temperature rise and insignificant or negative precipitation change trend, wheat yield exhibited negative impacts for Shaanxi $\left(\mathrm{GSAT}_{\text {slope }}=0.04 ; \mathrm{GSP}_{\text {slope }}=-0.013\right)$, Shanxi $\left(\mathrm{GSAT}_{\text {slope }}=\right.$ $\left.0.063 ; \mathrm{GSP}_{\text {slope }}=0.92\right)$, and Henan $\left(\mathrm{GSAT}_{\text {slope }}=0.039\right.$; $\left.\mathrm{GSP}_{\text {slope }}=0.071\right)$, with the loss of $0.917 \%, 1.316 \%$, and $1.921 \%$, respectively. If just from the aspect of quantitative values above, agricultural inputs were likely to be more important factors contributing to the formation of wheat yield. Nevertheless, one should note that agricultural inputs changes are mainly controlled by technological development level, and the impacts of agricultural inputs on crops can be stable in the premise that social and technological development are stable and the government pays more attention to the agricultural harvests, whereas climate change itself and its impacts on crops are both more complicated. Shortterm extreme weather events such as flood, drought, and frost will directly exert deadly effects on crops and sharply decrease their yield, while the effects of long-term trend of climate change is gradual and potential. Long-term climate

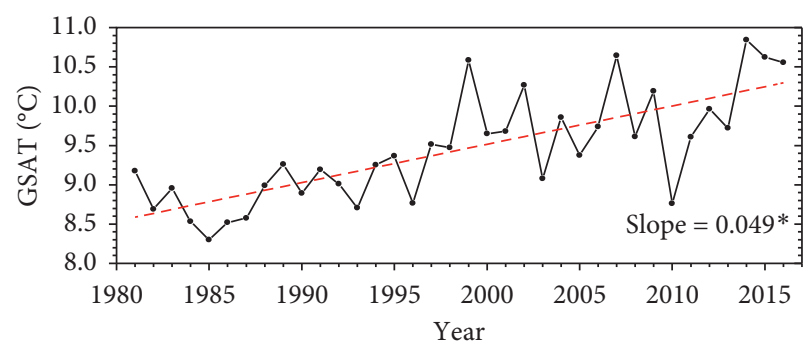

(a)

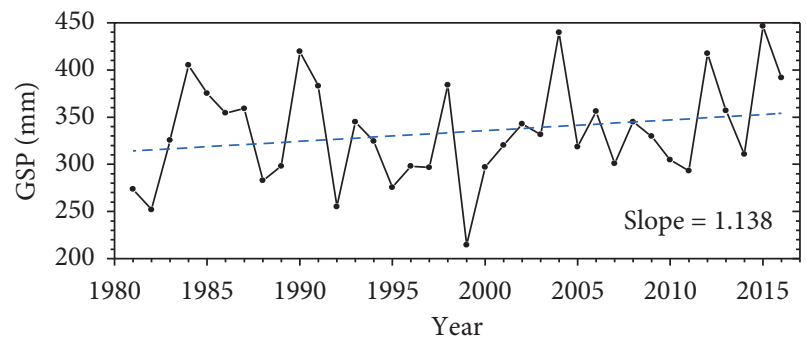

(b)

FIgURE 2: GSAT and GSP for winter wheat in 1981-2016. The red and blue dashed lines represent linear fitting of GSAT and GSP. *indicates that the slope is significant at the $1 \%$ level.

changes can greatly influence the cropping system, planting boundary, and planting structure and further influence the allocation and trade of national agricultural products. Therefore, the impacts of climatic factors on crops cannot be ignored, although apart from extreme climate events, it may be small in the short term.

3.3. Scenario Simulation Analysis of Climate Change. Figure 4 and Table 3 show the differences of GSAT and GSP projected for 2021-2050 relative to the baseline period of 1981-2005 for the medium emission scenario (RCP4.5) and high emission scenario (RCP8.5). The GSAT will increase by $1.33-1.44^{\circ} \mathrm{C}$ under RCP 4.5 and by $1.43-1.68^{\circ} \mathrm{C}$ under RCP8.5 for the five provinces (region), relative to the baseline period. Shanxi province will experience the most warming. In terms of the whole study area, GSAT is projected to experience a rise of about $1.37^{\circ} \mathrm{C}$ for RCP $4.5^{\circ} \mathrm{C}$ and $1.54^{\circ} \mathrm{C}$ for RCP8.5. The results also suggested that there will be an increasing trend in GSP for the majority of the regions under the two RCP scenarios, except for a slight decrease in western Shaanxi province. Shandong province will experience the most precipitation increasing. The precipitation increment 


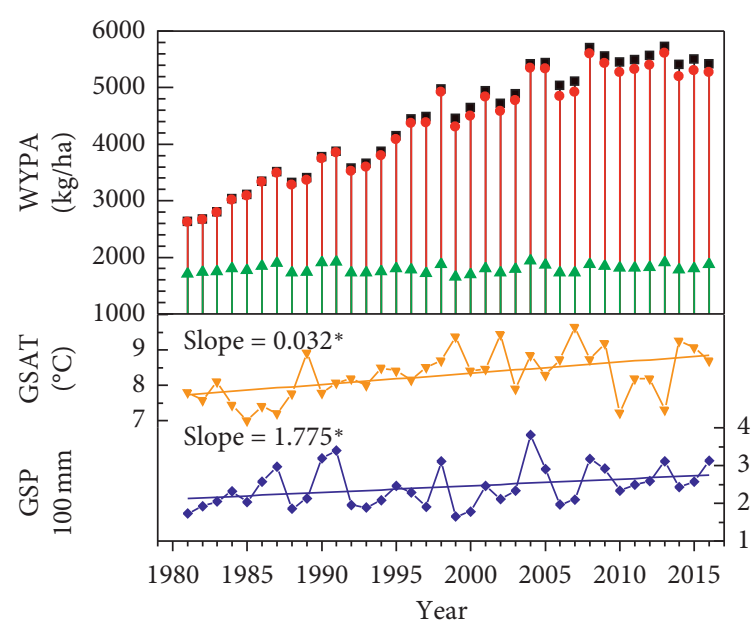

(a)

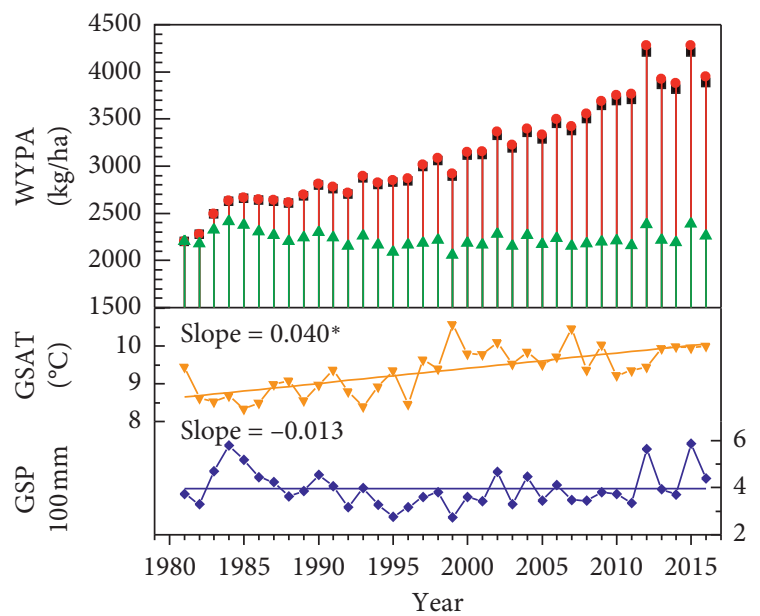

(c)

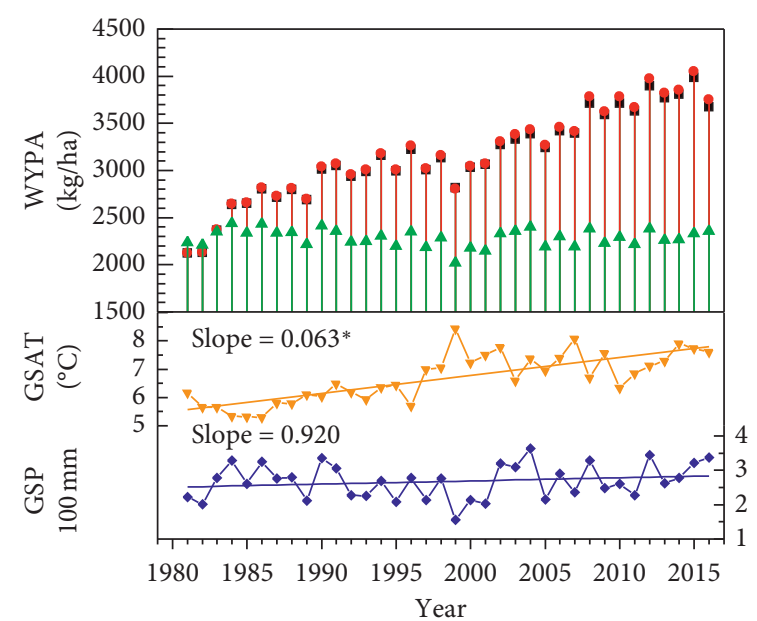

(b)

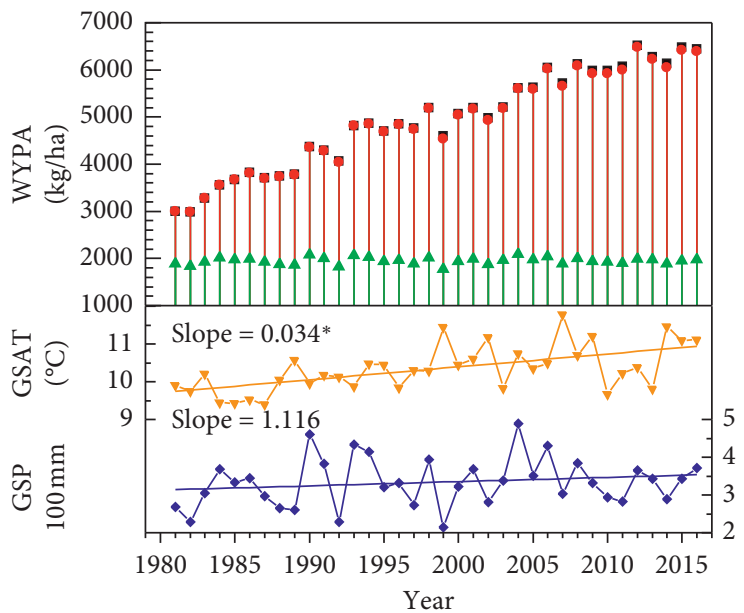

(d)

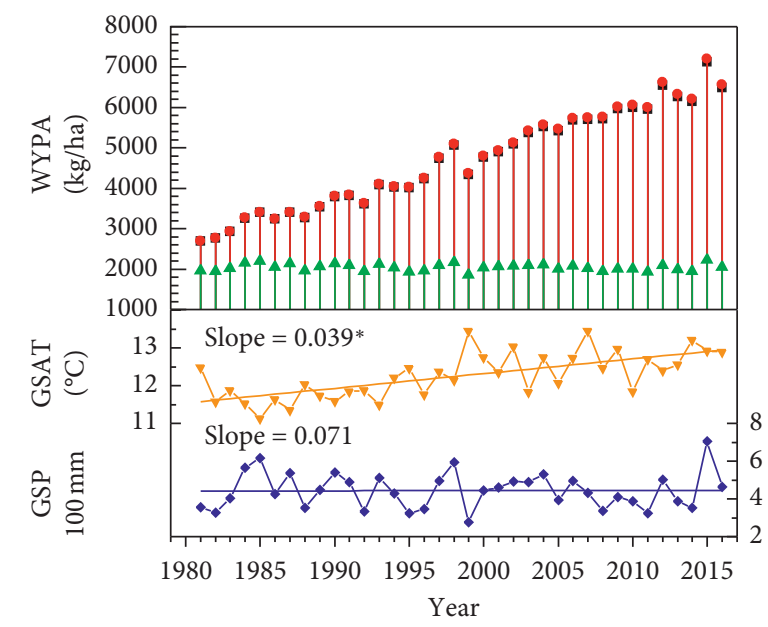

(e)

FIGURE 3: Model-predicted WYPA with observed climatic data and agricultural inputs (black squares) detrended climatic data and observed agricultural inputs (red dots) and observed climatic data and fixed agricultural inputs (green triangles). Yellow triangles (lines) and blue diamonds (lines) represent the (trends of) GSAT and GSP for winter wheat. * represents the trends are significant at 5\% level. (a) Jing-jin-ji. (b) Shanxi. (c) Shaanxi. (d) Shandong. (e) Henan. 


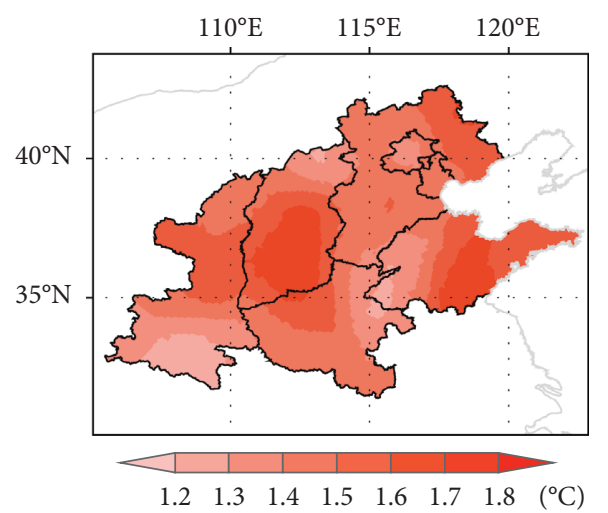

(a)

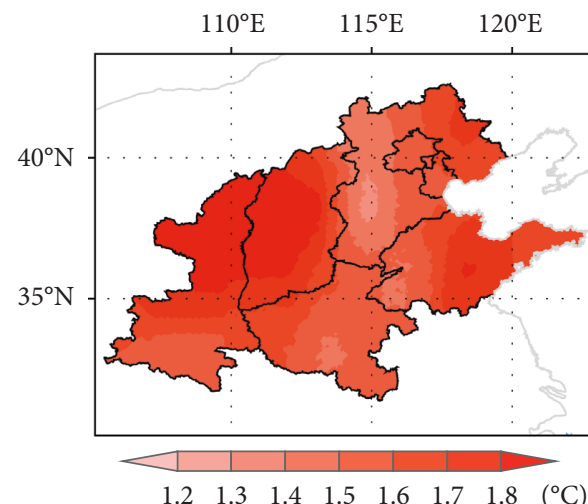

(c)

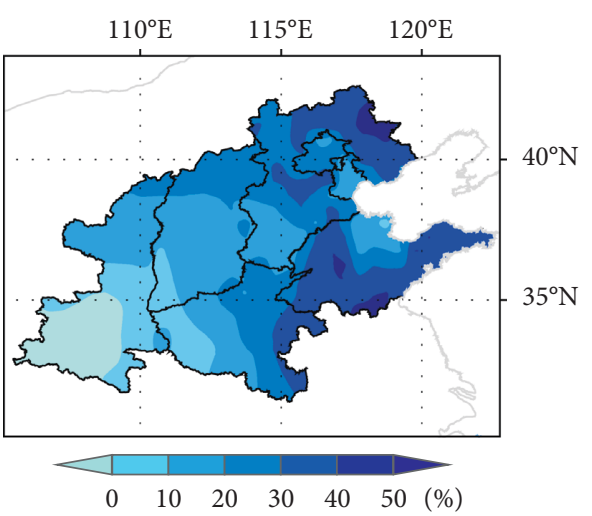

(b)

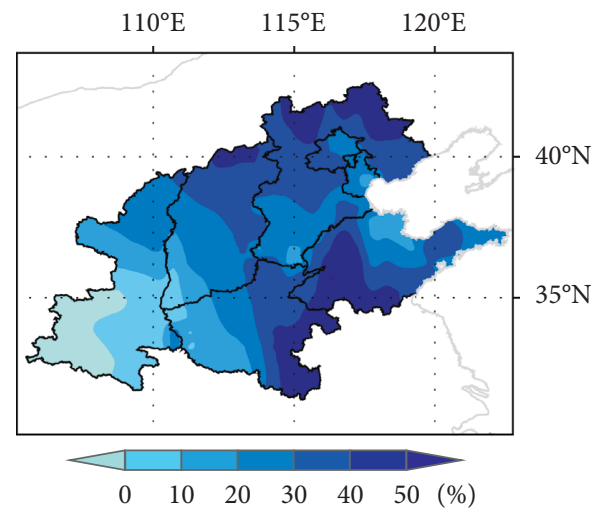

(d)

FIgURE 4: The differences of GSAT and GSP projected for 2021-2050 relative to 1981-2005 under RCP4.5 and RCP8.5. (a) GSAT under RCP 4.5. (b) GSP under RCP 4.5. (c) GSAT under RCP 8.5. (d) GSP under RCP 8.5.

TABle 3: The differences of GSAT and GSP for each province (region) in 2021-2050 relative to that in 1981-2005 under RCP4.5 and RCP8.5.

\begin{tabular}{lcccc}
\hline & \multicolumn{2}{c}{ GSAT $\left({ }^{\circ} \mathrm{C}\right)$} & \multicolumn{2}{c}{ GSP (\%) } \\
& RCP4.5 & RCP8.5 & RCP4.5 & RCP8.5 \\
\hline Jing-jin-ji & 1.38 & 1.43 & 25.13 & 30.38 \\
Shanxi & 1.44 & 1.68 & 17.12 & 19.33 \\
Shaanxi & 1.33 & 1.63 & 2.72 & 4.53 \\
Shandong & 1.40 & 1.55 & 31.82 & 33.00 \\
Henan & 1.34 & 1.47 & 17.14 & 25.30 \\
All & 1.37 & 1.54 & 17.31 & 22.22 \\
\hline
\end{tabular}

under high emissions scenario is much more than that under medium emissions scenario. The GSP increment for the five provinces (region) under RCP4.5 and RCP8.5 are 2.72$31.82 \%$ and $4.53-33.0 \%$, respectively. In terms of the whole study area, precipitation is projected to increase by $17.31 \%$ for RCP 4.5 and by $22.22 \%$ for RCP8.5.

Finally and for perspective, we used the estimates of climate change under RCP4.5 and RCP8.5 (Table 3) to obtain estimates of the effects of projected GSAT and GSP changes on WYPA variance in the five provinces (region) (Table 4). The change tendency of WYPA is opposite to GSAT but is consistent with GSP. For RCP4.5, temperature rising gives a decrease of $1.75 \%$ in average WYPA for the whole study area and a decrease of $1.46 \%$ (Jing-Jin-Ji region) to $2.71 \%$ (Shanxi province) for the selected five
TABLE 4: Effects of climate change on WYPA for each province (region) in 2021-2050 under RCP4.5 and RCP8.5.

\begin{tabular}{lcccccc}
\hline & \multicolumn{2}{c}{$\begin{array}{c}\text { Effects of GSAT } \\
(\%)\end{array}$} & \multicolumn{2}{c}{$\begin{array}{c}\text { Effects of GSP } \\
(\%)\end{array}$} & \multicolumn{2}{c}{$\begin{array}{c}\text { Comprehensive } \\
\text { effect }(\%)\end{array}$} \\
& RCP4.5 & RCP8.5 & RCP4.5 & RCP8.5 & RCP4.5 & RCP8.5 \\
\hline Jing-jin-ji & -1.46 & -1.51 & 4.67 & 5.65 & 3.22 & 4.14 \\
Shanxi & -2.71 & -3.16 & 3.18 & 3.60 & 0.47 & 0.43 \\
Shaanxi & -1.80 & -2.21 & 0.51 & 0.84 & -1.30 & -1.37 \\
Shandong & -1.79 & -1.98 & 5.92 & 6.14 & 4.13 & 4.16 \\
Henan & -1.56 & -1.72 & 3.19 & 4.71 & 1.62 & 2.99 \\
All & -1.75 & -1.97 & 3.22 & 4.13 & 1.47 & 2.16 \\
\hline
\end{tabular}

provinces (region). However, precipitation increasing is beneficial to the improvement of WYPA, with the increase of $3.22 \%$ for the whole study area and $0.51 \%$ (Shaanxi province) to $5.92 \%$ (Shandong province) for the five provinces (region). For RCP8.5, WYPA decreases by $1.97 \%$ for the whole study area and by $1.51 \%$ (Jing-jin-ji region) to $3.16 \%$ (Shanxi province) for the selected five provinces (region). Precipitation increasing gives a rise of $4.13 \%$ in WYPA for the whole study area, and $0.84 \%$ (Shaanxi province) to $6.14 \%$ (Shandong province) for the five provinces (region). In terms of the comprehensive effect of GSAT and GSP, the majority of study area experiences a WYPA increase, due to the substantial increase of GSP counteracting the negative effect of GSAT rising. However, the small increase in Shaanxi's GSP is not enough to offset 
the negative effects driven by the large increase in GSAT, which causes Shaanxi to be the only province whose WYPA suffering from the projected changes of GSAT and GSP. For RCP4.5, WYPA increases by $1.47 \%$ for the whole study area and by $0.47-4.13 \%$ for Shanxi, Henan, Jing-Jin-Ji, and Shandong provinces, but decreases by $1.3 \%$ for Shaanxi province. For RCP8.5, WYPA increases by $2.16 \%$ for the whole region and by $0.43-4.16 \%$ for Shanxi, Henan, JingJin-Ji, and Shandong provinces, while Shaanxi province experiences a wheat yield decrease of $1.37 \%$.

\section{Discussion}

4.1. Climate Model Uncertainty. Climate models are one of the most important tools to simulate and forecast future climate change, but there exists uncertainty about the results simulated by different climate models, which represents a key challenge for adaptation planning. For example, Ding et al. [47] simulated the climate change of China by the 40 models and suggested that there is a potential significant warming in China in the twenty-first century under different emission scenarios. However, large uncertainty exists in the projection of precipitation, and further studies are needed. $\mathrm{Xu}$ and $\mathrm{Xu}$ [48] assessed the performance in simulating the climate over China based on the CMIP3 and CMIP5 experiments and found that models appeared to have a good performance on reproducing the warming tendency but showing limited skills for precipitation, and most models overestimate precipitation. Uncertainty in future climate change derives from various sources such as emission scenarios, model structure, downscaling/bias-correction methods, and impact models [49].

In this study, we dealt with the uncertainty of the model from the following three aspects. Firstly, in emissions scenarios, we selected RCP4.5 as the lower one because it is possibly most consistent with the future economic development of China and meets the mitigation plan for responding to climate change [33]. The upper bound of four RCPs, RCP8.5, was used as the contrast scenario. Secondly, the climate simulation datasets used in this study were obtained from the ISI-MIP, which have been bias-corrected in the fasttrack of ISI-MIP using the trend-preserving method and can reproduce the observed climate very well [35]. Several studies have demonstrated the value of using the same projections by the 5 GCMs in climate change impact assessments for different sectors at the global and regional scales [50-54]. Thirdly, we used the MME to reduce the uncertainty because combining models can generally increase the skill, reliability, and consistency of model forecasts [55]. The combined information of an equally weighted average of several models (the method used in this study) is usually found to agree better with observations than any single model [56]. These solutions can effectively reduce the uncertainty of the models and improve the accuracy of our analysis.

4.2. Food Security and Adaptation Strategies. China is a large producer and consumer of food. China's domestic demand for food maintained a self-sufficiency rate of $95 \%$, while the other $5 \%$ depended on the international market for balance, since joining the WTO in 1980 [57]. However, with the growing population and rising consumption levels, China needs more food to feed itself. According to the forecast of the DRC (Development Research Center of the State Council), total domestic grain demand will reach 584.87-592.02 million tons, and the gap between food supply and demand will be up to 40-50 million tons [58]. The problem of food shortage has become more and more serious in recent years, and the reasons for food shortage are various factors, among which included are the increase of population, the decrease of cultivated land area, and the degradation of cultivated land quality. In addition, climate change has altered the agrometeorological conditions and posed a certain impact on crops growth. As shown in the results of this paper, the contribution of temperature rising to winter wheat yield in Northern China was negative since 1981, and the degree of influence will increase with the temperature rising further, while precipitation had a positive impact.

It is suggested that China could take the following two aspects to ensure the supply of domestic wheat, i.e., domestic wheat production and international wheat trade. From the aspect of domestic wheat production, climate change has been a concern of policy-makers, scientists, and farmers due to its far-reaching impacts on agriculture, and appropriate adaptation strategies should be taken immediately. Because Northern China is the principal wheat production base, the climate adaptation measures proposed in the following are based on the climate change of this region. Firstly, one of the most realistic and convenient measures for the local farmers is adjusting the sowing dates of winter wheat. Studies found that the suitable sowing dates of winter wheat in the region have been delayed in the last few decades and are projected to be further delayed in the future due to the temperature rising [59, 60]. The properly delayed sowing dates could result in significant differences in environmental conditions during crop grain filling and usually help the grains grow with increasing temperatures, which will minimize the decreasing rate of wheat yield under global warming [61, 62]. It is noticeable, however, that the freeze injury before winter wheat overwintering must be considered in this region, so the sowing dates cannot be delayed too late. Secondly, the strategy that copes with the challenges of climate change is to plant new grains which have higher heat requirement and longer duration of reproductive growth period. Better adaption to warmer climatic conditions makes these new grains more favorable than old ones under climate change and significantly increases wheat yield [63, 64]. Thirdly, converting the tillage system from conventional plow tillage to rotary tillage is beneficial to improve the efficiency of local agriculture production and enhance crop yield. The conventional plow tillage is time-consuming and energyintensive, and farmers prefer to burn crop residues in order to save time for seeding the next crop, which has some adverse impacts on soil and hinders crops growth. However, rotary tillage can chop crop residue and mix it into the soil, which will increase retention of rainfall in the soil and enhance SOC sequestration. This can enhance the ability of wheat to cope with climate change during its growing period 
[65]. Fourthly, it is necessary to expand irrigation infrastructure for Northern China. Although this study found that the precipitation likely increases during wheat growing season over the region, winter wheat is generally cultivated under irrigation conditions due to the small amount and large fluctuation of precipitation [66]. Optimizing irrigation facilities can ensure the water supply for wheat during the critical growth period, which is beneficial to improve its ability to cope with adverse climatic conditions and reduce the losses of wheat yield. In addition, there are many other options of agricultural adaptation to climate change for the region, such as developing crop diversity, improving fertilization, and natural resource management. Finally, we should be aware that the negative impacts of climate change could be moderated by implementing these adaptations duly and steadily rather than missing the appropriate timing to implement adaptations.

In terms of international wheat trade, China should make full use of the grain production resources in other countries and regions and expand the sources of domestic food supply through food trade and cooperation, so as to keep the balance between food supply and demand and guarantee the quantity of the grain stored. However, China's import market of wheat in international trade mainly focuses in the United States, Canada, and Australia. For instance, China imported $99 \%$ of its wheat from the three countries in 2011, which will raise the potential risk for China's wheat import market in the future. China should try to reduce the risk of wheat imports by analyzing the potential of wheat yield increase and export in various countries and seeking more stable sources for wheat importing. For example, from climate perspective, the United States, the largest wheat exporter to China, is projected to experience a wheat yield decrease in the future while Canada is inversed [15, 67-70]. This indicates that China's wheat import market center in North America may slowly shift from the United States to Canada. Moreover, as emerging export countries in the international wheat trade market, Russia, Ukraine, and Kazakhstan have witnessed a rapid increasing in the proportion of wheat export and a growing market influence [71]. Climate change has effectively increased their grain production potential because of the location in mid- and high-latitudes [72, 73]. The food self-sufficiency rate of the three countries has been stable at more than $100 \%$, and the export potential is also increasing (FAOSTAT food balance sheet). Therefore, China can increase its wheat import from these countries to ensure the domestic food security in the future.

\section{Conclusion}

The relative contribution of climatic factors to wheat yield was about $0.762-1.921 \%$ in absolute terms for the period 19812016, which was smaller than the contribution of agricultural inputs and technological progress that ranged from 27.193 to $60.438 \%$. Warming trends during winter wheat growing season had a negative effect on WYPA, whereas the increasing trend of precipitation had a positive effect in 1981-2016, and the elastic coefficients were -0.109 and 0.186 , respectively. This indicated that a $1 \%$ rise in GSAT tends to lower yield of $0.109 \%$, and a $1 \%$ increase in GSP increases yield of $0.186 \%$, up to a point at which further rainfall becomes harmful. The GSAT and GSP are both projected to increase in the study area for the period of 2021-2050, the increment of which for high emission scenario (RCP8.5) is more than that for medium emission scenario (RCP4.5). GSAT is projected to rise $1.37^{\circ} \mathrm{C}$ under RCP4.5 scenario and $1.54^{\circ} \mathrm{C}$ under RCP8.5 scenario for the whole study area, which will lower the average WYPA by $1.75 \%$ and $1.97 \%$, respectively. GSP is tended to increase by $17.31 \%$ under RCP 4.5 scenario and $22.22 \%$ under RCP8.5 scenario for the whole region, which will give a rise of $3.22 \%$ and $4.13 \%$ in WYPA, respectively. In terms of the comprehensive effect of GSAT and GSP, average WYPA will increase by $1.47 \%$ under RCP4.5 scenario and $2.16 \%$ under RCP8.5 scenario for the whole study area. At provincial scale, the changes of climatic factors will have a positive effect on WYPA for Jing-Jin-Ji region, Shanxi, Shandong, and Henan provinces, while they will have a negative effect for Shaanxi province.

\section{Data Availability}

The meteorological observation data were taken from http:// data.cma.cn/data/cdcindex/cid/6d1b5efbdcbf9a58.html. The climate scenario data were downloaded from https://esg.pikpotsdam.de/search/isimip-ft/. The agricultural data were provided by http://data.stats.gov.cn/. The other data used to support the findings of this study are available from the corresponding author upon request.

\section{Conflicts of Interest}

The authors declare that there are no conflicts of interest regarding the publication of this paper.

\section{Acknowledgments}

This research was supported by the grants (to IGSNRR) from the Ministry of Science and Technology of the People's Republic of China (2016YFA0602704) and the National Natural Science Foundation of China (41831174 and 41671201).

\section{References}

[1] IPCC, Climate Change 2013: the Physical Scientific Basis. Contribution of Working Group I to the Fifth Assessment Report of the Intergovernmental Panel on Climate Change, Cambridge University Press, Cambridge, UK, 2013.

[2] R. P. Motha and W. Baier, "Impacts of present and future climate change and climate variability on agriculture in the temperate regions: North America," Climatic Change, vol. 70, no. 1-2, pp. 137-164, 2005.

[3] M. J. Salinger, "Climate variability and change: past, present and future: an overview," Climatic Change, vol. 70, no. 1-2, pp. 9-29, 2005.

[4] K. Boomiraj, S. P. Wani, K. K. Garg, P. K. Aggarwal, and K. Palanisamp, "Climate change adaptation strategies for agro-ecosystem-a review," Journal of Agrometeorology, vol. 12, no. 2, pp. 145-160, 2010. 
[5] C. Rosenzweig, J. Elliott, D. Deryng et al., "Assessing agricultural risks of climate change in the 21st century in a global gridded crop model intercomparison," Proceedings of the National Academy of Sciences, vol. 111, no. 9, pp. 3268-3273, 2014.

[6] R. Mendelsohn, W. Morrison, M. E. Schlesinger, and N. G. Andronova, "Country-specific market impacts of climate change," Climatic Change, vol. 45, no. 3-4, pp. 553-569, 2000.

[7] C. Baker-Austin, J. A. Trinanes, N. G. H. Taylor, R. Hartnell, A. Siitonen, and J. Martinez-Urtaza, "Emerging vibrio risk at high latitudes in response to ocean warming," Nature Climate Change, vol. 3, no. 1, pp. 73-77, 2013.

[8] C. Rosenzweig and D. Hillel, Climate Change and the Global Harvest: Potential Impacts on the Greenhouse Effect on Agriculture, Oxford University Press, New York, NY, USA, 1998.

[9] J. Wilcox and D. Makowski, "A meta-analysis of the predicted effects of climate change on wheat yields using simulation studies," Field Crops Research, vol. 156, no. 2, pp. 180-190, 2014.

[10] P. Kurukulasuriya and S. Rosenthal, Climate Change and Agriculture: A Review of Impacts and Adaptations, World Bank, Washington, DC, USA, 2003.

[11] G. Fischer, M. Shah, F. N. Tubiello, and H. van Velhuizen, "Socio-economic and climate change impacts on agriculture: an integrated assessment, 1990-2080," Philosophical Transactions of the Royal Society B: Biological Sciences, vol. 360, no. 1463, pp. 2067-2083, 2005.

[12] B. Smit and O. Pilifosova, "Adaptation to climate change in the context of sustainable development and equity," in Climate Change 2001: Impacts, Adaptations and Vulnerability. The Third Assessment Report of the Intergovernmental Panel on Climate Change, J. McCarthy, O. Canziana, N. Leary, D. Dokken, and K. White, Eds., pp. 879-967, Cambridge University Press, Cambridge, UK, 2001.

[13] D. S. G. Thomas and C. Twyman, "Equity and justice in climate change adaptation amongst natural-resourcedependent societies," Global Environmental Change, vol. 15, no. 2, pp. 115-124, 2005.

[14] National Bureau of Statistics of China, China Statistical Year Book 2009, China Statistics Press, Beijing, China, 2009, in Chinese.

[15] C. Zhao, B. Liu, S. Piao et al., "Temperature increase reduces global yields of major crops in four independent estimates," Proceedings of the National Academy of Sciences, vol. 114, no. 35, pp. 9326-9331, 2017.

[16] J. X. Song, "A review of research methods of the effect of climate change on agriculture," Science and Technology for Development, vol. 12, no. 6, pp. 765-776, 2016.

[17] W. Shi, F. Tao, and Z. Zhang, "A review on statistical models for identifying climate contributions to crop yields," Journal of Geographical Sciences, vol. 23, no. 3, pp. 567-576, 2013.

[18] H. Gitay, W. Easterling, and B. Jallow, "Ecosystems and their goods and services," in Climate Change 2001: Impacts, Adaptation, and Vulnerability. The Third Assessment Report of the Intergovernmental Panel on Climate Change, J. McCarthy, O. Canziana, N. Leary, D. Dokken, and K. White, Eds., pp. 235-342, Cambridge University Press, Cambridge, UK, 2001.

[19] D. B. Lobell and C. B. Field, "Global scale climate-crop yield relationships and the impacts of recent warming," Environmental Research Letters, vol. 2, no. 1, article 014002, 2007.
[20] W. Schlenker and D. B. Lobell, "Robust negative impacts of climate change on African agriculture," Environmental Research Letters, vol. 5, no. 1, article 014010, 2010.

[21] F. Tao and Z. Zhang, "Adaptation of maize production to climate change in North China Plain: quantify the relative contributions of adaptation options," European Journal of Agronomy, vol. 33, no. 2, pp. 103-116, 2010.

[22] S. Asseng, F. Ewert, P. Martre et al., "Rising temperatures reduce global wheat production," Nature Climate Change, vol. 5, no. 2, pp. 37-64, 2014.

[23] D. B. Lobell and M. B. Burke, "On the use of statistical models to predict crop yield responses to climate change," Agricultural and Forest Meteorology, vol. 150, no. 11, pp. 1443-1452, 2010.

[24] C.-C. Chen, B. A. McCarl, and D. E. Schimmelpfennig, "Yield variability as influenced by climate: a statistical investigation," Climatic Change, vol. 66, no. 1-2, pp. 239-261, 2004.

[25] S. Barrios, B. Ouattara, and E. Strobl, "The impact of climatic change on agricultural production: is it different for Africa?," Food Policy, vol. 33, no. 4, pp. 287-298, 2008.

[26] M. Dell, B. F. Jones, and B. A. Olken, "What do we learn from the weather? The new climate-economy literature," Journal of Economic Literature, vol. 52, no. 3, pp. 740-798, 2014.

[27] E. Blanc and W. Schlenker, "The use of panel models in assessments of climate impacts on agriculture," Review of Environmental Economics and Policy, vol. 11, no. 2, pp. 258-279, 2017.

[28] J. Chou, W. Dong, and D. Ye, "Construction of a novel economy-climate model," Chinese Science Bulletin, vol. 51, no. 14, pp. 1735-1736, 2006.

[29] J. Chou, W. Dong, and G. Feng, "The methodology of quantitative assess economic output of climate change," Chinese Science Bulletin, vol. 56, no. 13, pp. 1333-1335, 2011.

[30] G. C. Zhao, "Study on Chinese wheat planting regionalization," Journal of Triticeae Crops, vol. 30, no. 5, pp. 886-895, 2010.

[31] S. B. Jin, Wheat Science in China, China Agriculture Press, Beijing, China, 1996, in Chinese.

[32] D. P. van Vuuren, J. Edmonds, M. Kainuma et al., "The representative concentration pathways: an overview," Climatic Change, vol. 109, no. 1-2, pp. 5-31, 2011.

[33] C. Gao, Z. T. Zhang, S. Chen, and Q. Liu, "The high-resolution simulation of climate change model under RCP4.5 scenarios in the Huaihe River Basin," Geographical Research, vol. 33, no. 3, pp. 467-477, 2014

[34] K. Riahi, S. Rao, V. Krey et al., "RCP 8.5-a scenario of comparatively high greenhouse gas emissions," Climatic Change, vol. 109, no. 1-2, pp. 33-57, 2011.

[35] S. Hempel, K. Frieler, L. Warszawski, J. Schewe, and F. Piontek, "A trend-preserving bias correction \&ndash; the ISI-MIP approach," Earth System Dynamics, vol. 4, no. 2, pp. 219-236, 2013.

[36] National Bureau of Statistics of China, China Compendium of Statistics 1949-2008, China Statistical Press, Beijing, China, 2010, in Chinese.

[37] C. Hsiao, The Analysis of Panel Data, Cambridge University Press, Cambridge, UK, 2003.

[38] A. Levin, C.-F. Lin, and C.-S. J. Chu, "Unit root tests in panel data: asymptotic and finite-sample properties," Journal of Econometrics, vol. 108, no. 1, pp. 1-24, 2002.

[39] G. S. Maddala and S. Wu, "A comparative study of unit root tests with panel data and a new simple test," Oxford Bulletin of Economics and Statistics, vol. 61, no. s1, pp. 631-652, 1999. 
[40] G. Q. Zhao, Econometrics, China Renmin University Press, Beijing, China, 2012, in Chinese.

[41] K.-C. Li, "Asymptotic optimality for \$C_p, C_L\$, crossvalidation and generalized cross-validation: discrete index set," The Annals of Statistics, vol. 15, no. 3, pp. 958-975, 1987.

[42] C. J. Willmott, "Some comments on the evaluation of model performance," Bulletin of the American Meteorological Society, vol. 63, no. 11, pp. 1309-1313, 1982.

[43] J. M. Yang, J. Y. Yang, S. Dou, X. M. Yang, and G. Hoogenboom, "Simulating the effect of long-term fertilization on maize yield and soil C/N dynamics in Northeastern China using DSSAT and CENTURY-based soil model," Nutrient Cycling in Agroecosystems, vol. 95, no. 3, pp. 287303, 2013.

[44] J. Moncrieff, R. Clement, J. Finnigan, and T. Meyers, "Averaging, detrending, and filtering of eddy covariance time series," in Handbook of Micrometeorology, X. Lee, W. Massman, and B. Law, Eds., vol. 29, pp. 7-31, Atmospheric and Oceanographic Sciences Library, Springer, Dordrecht, Netherlands, 2004.

[45] Z. Sun, S. F. Jia, A. F. Lv, K. J. Yang, J. Svensson, and Y. C. Gao, "Impacts of climate change on growth period and planting boundaries of winter wheat in China under RCP4.5 scenario," Earth System Dynamics Discussions, vol. 6, no. 2, pp. 21812210, 2015.

[46] S. Thaler, J. Eitzinger, M. Trnka, and M. Dubrovsky, "Impacts of climate change and alternative adaptation options on winter wheat yield and water productivity in a dry climate in Central Europe," Journal of Agricultural Science, vol. 150, no. 5, pp. 537-555, 2012.

[47] Y. Ding, G. Ren, Z. Zhao et al., "Detection, causes and projection of climate change over China: an overview of recent progress," Advances in Atmospheric Sciences, vol. 24, no. 6, pp. 954-971, 2007.

[48] Y. Xu and C. H. Xu, "Preliminary assessment of simulations of climate changes over China by CMIP5 multi-models," Atmospheric and Oceanic Science Letters, vol. 5, no. 6, pp. 489-494, 2012.

[49] G. Leng, Q. Tang, and S. Rayburg, "Climate change impacts on meteorological, agricultural and hydrological droughts in China," Global and Planetary Change, vol. 126, pp. 23-34, 2015.

[50] F. Piontek, C. Müller, T. A. M. Pugh et al., "Multisectoral climate impact hotspots in a warming world," Proceedings of the National Academy of Sciences, vol. 111, no. 9, pp. 32333238, 2014.

[51] J. Elliott, D. Deryng, C. Müller et al., "Constraints and potentials of future irrigation water availability on agricultural production under climate change," Proceedings of the National Academy of Sciences, vol. 111, no. 9, pp. 3239-3244, 2014.

[52] Y. Yin, D. Ma, S. Wu, and T. Pan, "Projections of aridity and its regional variability over China in the mid-21st century," International Journal of Climatology, vol. 35, no. 14, pp. 4387-4398, 2015.

[53] K. Frieler, S. Lange, F. Piontek et al., "Assessing the impacts of $1.5^{\circ} \mathrm{C}$ global warming-simulation protocol of the intersectoral impact model intercomparison project (ISIMIP2b)," Geoscientific Model Development, vol. 10, no. 12, pp. 4321-4345, 2017.

[54] X. Ma, C. Zhao, H. Tao, J. Zhu, and Z. W. Kundzewicz, "Projections of actual evapotranspiration under the $1.5^{\circ} \mathrm{C}$ and $2.0^{\circ} \mathrm{C}$ global warming scenarios in sandy areas in Northern China," Science of the Total Environment, vol. 645, no. 15, pp. 1496-1508, 2018.
[55] C. Tebaldi and R. Knutti, "The use of the multi-model ensemble in probabilistic climate projections," Philosophical Transactions of the Royal Society A: Mathematical, Physical and Engineering Sciences, vol. 365, no. 1857, pp. 2053-2075, 2007.

[56] S. J. Lambert and G. J. Boer, "CMIP1 evaluation and intercomparison of coupled climate models," Climate Dynamics, vol. 17, no. 2-3, pp. 83-106, 2001.

[57] X. N. Ren, The Impacts of Climate Change on China's Grain Production and Trade, Chinese Academy of Agricultural Sciences, Beijing, China, 2012, in Chinese.

[58] Development Research Center of the State Council, Research on Modernization of Agriculture with Chinese Characteristics, China Development Press, Beijing, China, 2012, in Chinese.

[59] D. Xiao, F. Tao, Y. Liu et al., "Observed changes in winter wheat phenology in the North China Plain for 1981-2009," International Journal of Biometeorology, vol. 57, no. 2, pp. 275-285, 2013.

[60] Z. Hao, X. Geng, F. Wang, and J. Zheng, "Impacts of climate change on agrometeorological indices at winter wheat overwintering stage in Northern China during 2021-2050," International Journal of Climatology, vol. 38, no. 15, pp. 5576-5588, 2018.

[61] K. D. Subedi, B. L. Ma, and A. G. Xue, "Planting date and nitrogen effects on grain yield and protein content of spring wheat," Crop Science, vol. 47, no. 1, pp. 36-44, 2007.

[62] D. Y. Ding, H. Feng, Y. Zhao, J. Q. He, Y. F. Zou, and J. M. Jin, "Modifying winter wheat sowing date as an adaptation to climate change on the loess plateau," Agronomy Journal, vol. 108 , no. 1 , pp. 53-63, 2016.

[63] F. Tao, S. Zhang, and Z. Zhang, "Spatiotemporal changes of wheat phenology in China under the effects of temperature, day length and cultivar thermal characteristics," European Journal of Agronomy, vol. 43, pp. 201-212, 2012.

[64] X. Zhang, S. Wang, H. Sun, S. Chen, L. Shao, and X. Liu, "Contribution of cultivar, fertilizer and weather to yield variation of winter wheat over three decades: a case study in the North China Plain," European Journal of Agronomy, vol. 50, pp. 52-59, 2013.

[65] H.-L. Zhang, X. Zhao, X.-G. Yin et al., "Challenges and adaptations of farming to climate change in the North China Plain," Climatic Change, vol. 129, no. 1-2, pp. 213-224, 2015.

[66] J. Li, S. Inanaga, Z. Li, and A. E. Eneji, "Optimizing irrigation scheduling for winter wheat in the North China Plain," Agricultural Water Management, vol. 76, no. 1, pp. 8-23, 2005.

[67] J. Tack, A. Barkley, and L. L. Nalley, "Effect of warming temperatures on US wheat yields," Proceedings of the National Academy of Sciences, vol. 112, no. 22, pp. 6931-6936, 2015.

[68] B. Liu, S. Asseng, C. Müller et al., "Similar estimates of temperature impacts on global wheat yield by three independent methods," Nature Climate Change, vol. 6, no. 12, pp. 1130-1136, 2016.

[69] B. Qian, H. Wang, Y. He, J. Liu, and R. De Jong, "Projecting spring wheat yield changes on the Canadian Prairies: effects of resolutions of a regional climate model and statistical processing," International Journal of Climatology, vol. 36, no. 10, pp. 3492-3506, 2016.

[70] B. D. Qian, R. D. Jong, T. Huffman, H. Wang, and J. Y. Yang, "Projecting yield changes of spring wheat under future climate scenarios on the Canadian Prairies," Theoretical and Applied Climatology, vol. 123, no. 3-4, pp. 651-669, 2016.

[71] I. Fehér and A. F. Fieldsend, The Potential for Expanding Wheat Production in Kazakhstan. Analysis from a Food 
Security Perspective, Publications Office of the European Union, Luxembourg, Europe, 2019.

[72] P. Mitra, M. Selowsky, and J. Zalduendo, Turmoil at Twenty: Recession, Recovery, and Reform in Central and Eastern Europe and the Former Soviet Union, World Bank, Washington, DC, USA, 2009.

[73] W. Liefert, O. Liefert, G. Vocke, and E. Allen, "Former Soviet Union region to play larger role in meeting world wheat needs," Amber Waves, vol. 8, no. 2, pp. 12-19, 2010. 

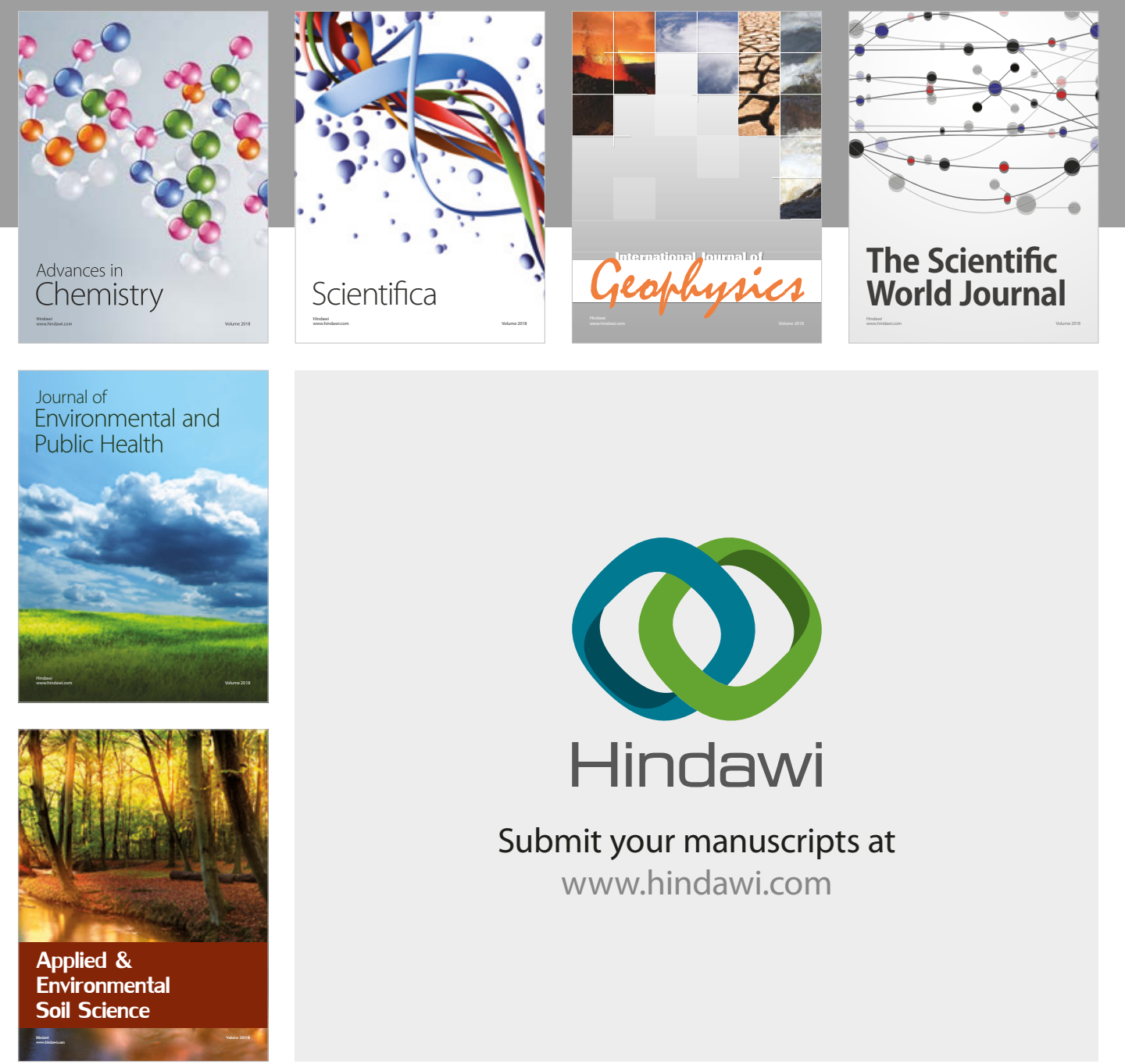

The Scientific

\section{World Journal}
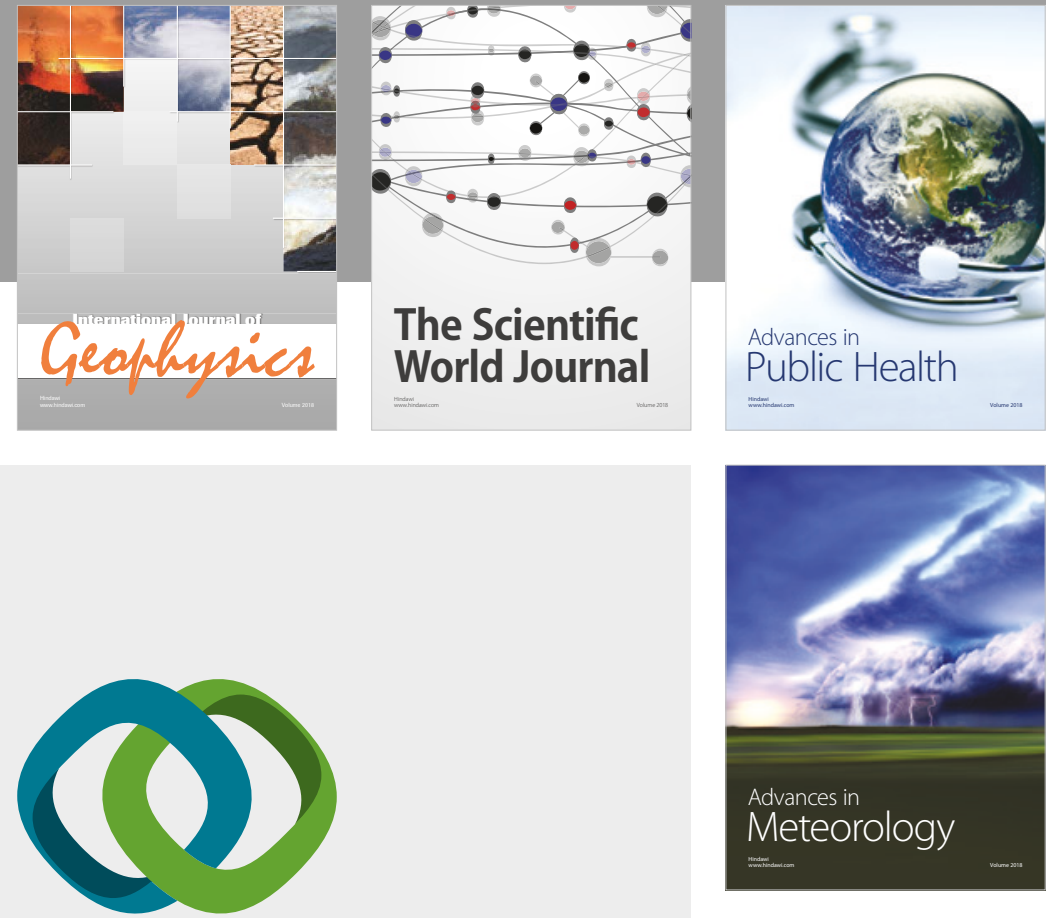

Advan

Public Health

\section{Hindawi}

Submit your manuscripts at

www.hindawi.com
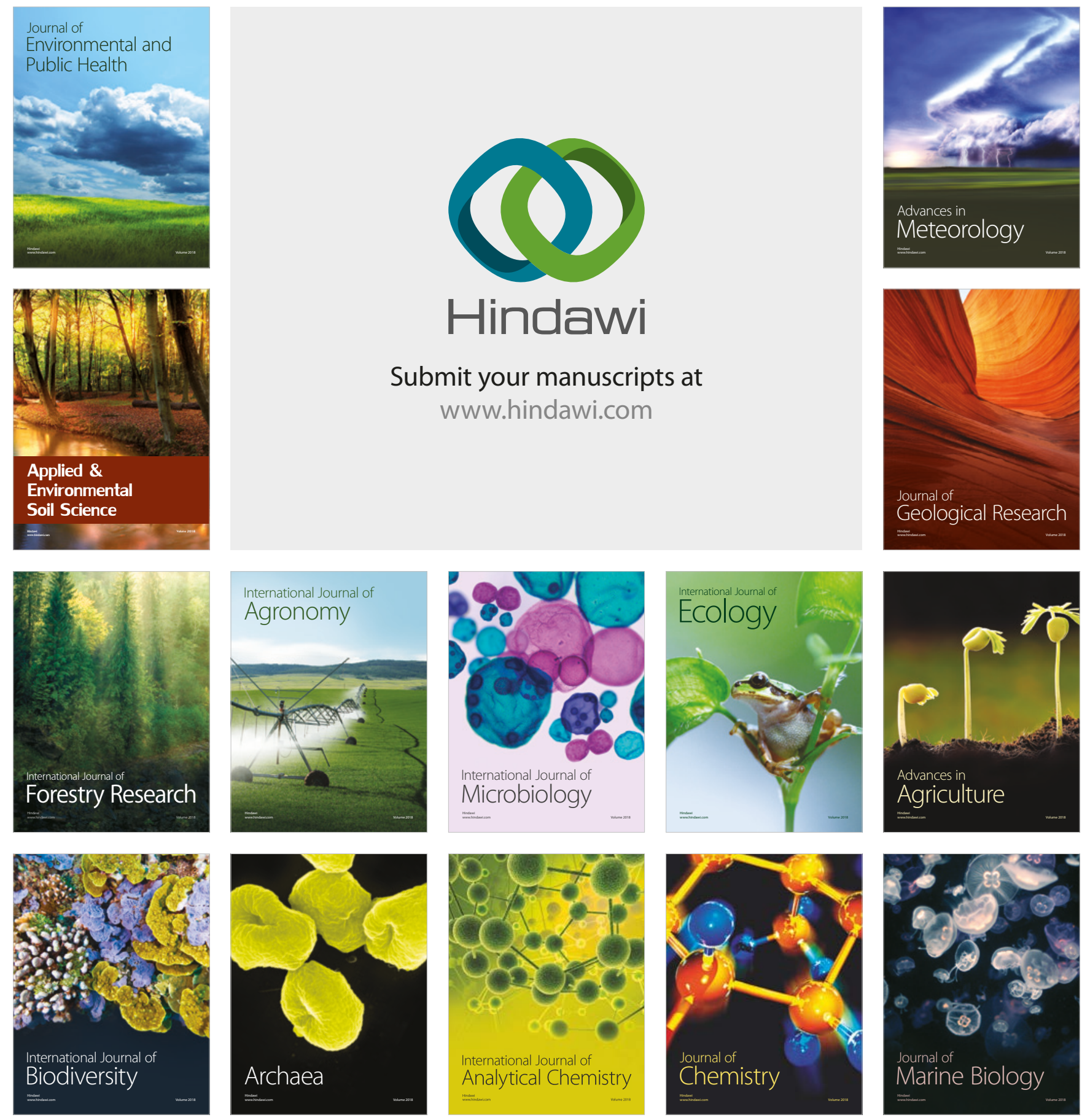